\title{
Managing Cable Thermal Stress through Predictive Ratings
}

\author{
R. Huang, J. A. Pilgrim and P. L. Lewin \\ School of Electronics and Computer Science \\ University of Southampton \\ Southampton, UK \\ rh5g10@ecs.soton.ac.uk
}

\author{
D. Scott and D. Morrice \\ National Grid plc \\ Warwick, UK
}

\begin{abstract}
The majority of high voltage cables are sized and operated by a continuous current rating which is based on the worst-case assumptions. However, the load on the cables themselves may vary significantly depending upon the time and season. In this paper, a dynamic thermal model for a cable in air installation is built using the finite difference method. The realtime load current and ambient conditions are accessible to allow improved cable modelling. This model is then used to support the rating calculations, the accuracy of which is compared with results obtained from laboratory experiments. A prediction system has been developed to predict the rating from any point forward within the next 24 hours.
\end{abstract}

Keywords-Cable; dynamic thermal rating; finite difference method; thermal analysis;

\section{INTRODUCTION}

The steady state, or continuous, current rating is usually used as the criteria to size and operate the high voltage cables. However, in most cases, the load on the cables themselves will not match original assumptions and may vary significantly depending upon the time of day, day of the week and season. Given the relatively short durations of peak loads and the comparatively long thermal time constants of high voltage cables, it is often possible to load cables beyond their continuous current rating without the cable exceeding its operating temperature limit. Many utilities are now beginning to use dynamic ratings as a method of using this additional capacity safely $[1,2,3]$, however this data is not available at the day ahead planning stage, which would be very valuable to network operators.

To solve this problem, it is necessary to employ a predictive rating method, capable of providing network operators with accurate short term current ratings at the day ahead stage. This has the double benefit of reducing variations in dynamic ratings (which makes them difficult to plan with), while reducing the risk of thermally overloading the cable, thus prematurely ageing the dielectric.

Cable in free air is a common kind of cable installation which can be seen where cables are used in substations or at the connection point with overhead lines. However, the IEC 60287 [4] and 60853 [5] standards, which are widely used in utilities, are based on very rough assumptions when dealing with the situation of a high voltage cable in free air.

In this paper, a dynamic thermal model for a cable in air installation is built using the finite difference method. The realtime load current is used to calculate the heat losses in the conductor and sheath of the cable, while measurements of ambient conditions are accessible to allow improved modelling of heat transfer. The dynamic thermal model is then used to support the rating calculations, the accuracy of which is compared to laboratory experiments. In addition, a day-ahead load forecasting system is built using the Support Vector Regression method and integrated in the dynamic thermal model. Thus, the rating can be predicted from any point forward within the next 24 hours, but with a minimal risk of thermally overstressing the cable.

\section{IEC MODEL FOR CABLE IN AIR}

The IEC 60287 standard [4] is theoretically able to calculate the steady-state rating for cable laid in free air both with and without solar radiation. Based on a large number of tests on various cables configurations which were carried out in UK during 1930s, an equation that represents the total thermal dissipation from cable surface to air was deduced to be:

$$
W_{t}=\pi D_{e}^{*} h\left(\Delta \theta_{s}\right)^{5 / 4}
$$

where $D_{e}{ }^{*}$ is the external diameter of the cable $(m), h$ is the heat dissipation coefficient $\left(W^{-2}(K)^{-5 / 4}\right), \Delta \theta_{s}$ is the excess of cable surface temperature above ambient temperature $(K)$. Thus, the thermal resistance $T_{4}$ external to the cable can be expressed as:

$$
T_{4}=\frac{1}{\pi D_{e}^{*} h\left(\Delta \theta_{s}\right)^{1 / 4}}
$$

The values of heat transfer coefficient, $h$, were obtained from experiments and fitted using:

$$
h=\frac{Z}{\left(D_{e}^{*}\right)^{g}}+E
$$


where constants $Z, E$ and $g$ are related to cable diameter for various cable arrangements are given in Table 2 in IEC 60287 [4]. After the value of $T_{4}$ for cable in air has been calculated, cable temperature and ratings can be obtained by the normal procedure as referred to IEC 60287 and IEC 60853 standards.

The method as defined tries to embody heat convection, radiation, conduction and mutual heating in a single heat transfer coefficient. However it restricts the use of the model for natural cooling. Furthermore the experimentally based equation is over-simplified and can't satisfy all cable geometries and arrangements. Morgan [6] has shown that exponent $1 / 4$ in (2) and heat transfer coefficient $h$ in (3) varies with the temperature rise of the cable surface. This is because the larger temperature rise of the cable surface will cause further reduction in air density, which will lead to greater air velocity. As a result, the heat transfer on cable surface will be faster, which gives an increase in $h$.

\section{FINITE DIFFENERCE METHOD}

Nowadays, numerical models can be easily computed to obtain more accurate results. In this work, the Finite Difference Method (FDM) is used to build a detailed model for a cable in air. Based on the assumption that the heat flow is radial both inside and outside the cable, a transient thermal model can be solved using the FDM in terms of both time and space.

\section{A. Cable Parameters}

The cable considered in this analysis is a $630 \mathrm{~mm}^{2}$ XLPE single phase cable with the geometry and materials shown in Table I.

TABLE I. CABLE GeOMETRY AND MATERIALS

\begin{tabular}{|c|c|c|}
\hline Component & Outer Diameter $(\mathbf{m m})$ & Material \\
\hline Conductor & 30.67 & Copper \\
\hline Conductor screen & 31.67 & Semicon \\
\hline Dielectric & 49.67 & XLPE \\
\hline Dielectric screen & 51.74 & Semicon \\
\hline Copper tape screen & 52.08 & Copper \\
\hline Inner sheath & 57.68 & PVC \\
\hline Tap bedding & 59.28 & Fabric \\
\hline Armour & 64.28 & Al/PPL \\
\hline Outer Sheath & 72.28 & PVC \\
\hline
\end{tabular}

\section{B. FDM Model}

To build a FDM model, this cable can be represented by the thermoelectric equivalent circuit shown in Fig. 1. Twenty-four nodes have been placed from conductor surface to the cable surface, with the locations defined in Table II.

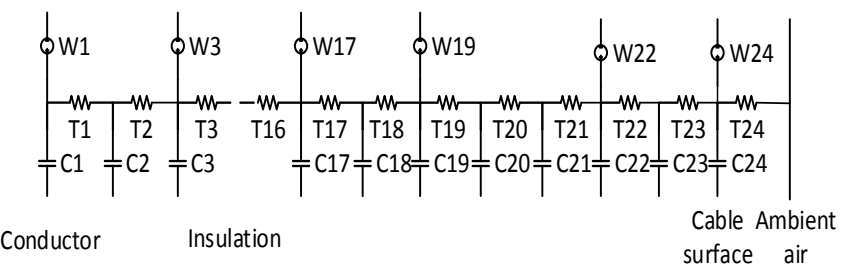

Fig. 1. Thermoelectric equivalent circuit for cable in air.
TABLE II. CABLE GEOMETRY AND MATERIALS

\begin{tabular}{|c|c|c|c|}
\hline Node & Location & Node & Location \\
\hline 1 & Conductor surface & 20 & $\begin{array}{c}\text { Midway through PVC } \\
\text { sheath }\end{array}$ \\
\hline 2 & Conductor screen surface & 21 & $\begin{array}{c}\text { Outer surface of fabric tap } \\
\text { bedding }\end{array}$ \\
\hline $3-17$ & Insulation & 22 & Outer surface of wire armour \\
\hline 18 & Insulation screen surface & 23 & $\begin{array}{c}\text { Log mean radius of PVC } \\
\text { outer sheath }\end{array}$ \\
\hline 19 & $\begin{array}{c}\text { Midway through copper } \\
\text { tape screen }\end{array}$ & 24 & Cable surface \\
\hline
\end{tabular}

The heat sources in the cable are represented by W1 (conductor losses), W3-W17 (dielectric losses), W19 (sheath losses) and W22 (armour losses), which are calculated based on IEC 60287 [4]. However, the conductor and sheath losses in this model are improved to be temperature dependant. If the cable is directly exposed to the solar radiation, W24 is used to take into account the heat from solar radiation. T1-T23 are used to simulate the thermal conduction between the nodes in the cable. $\mathrm{C} 1-\mathrm{C} 24$ are the thermal capacitances at each node. The temperature at each node is calculated using:

$$
\begin{gathered}
\frac{\theta_{n-1}(t)-\theta_{n}(t)}{T_{n-1}}-\frac{\theta_{n}(t)-\theta_{n+1}(t)}{T_{n}}+W_{n}(t-1) \\
=C_{n} \frac{\theta_{n}(t)-\theta_{n}(t-1)}{\Delta t}
\end{gathered}
$$

Where $n$ is the node number, $t$ is the time step, $\Delta t$ is the time step interval and $\theta_{n}(t)$ means the temperature at node $n$ and time $t$.

T24 is the thermal resistance to represent convection and radiation from cable surface to ambient free air. In this work, they are considered by natural convective heat transfer coefficients $h_{c o n v, n}$ and radiative heat transfer coefficients $h_{r a d}$ such that:

$$
\begin{gathered}
h_{c o n v, n}=\frac{k_{a i r} c(G r \cdot \operatorname{Pr})^{m}}{D_{e}^{*}} \\
h_{r a d}=\frac{\sigma K_{r} k_{r}\left[\left(\theta_{e}+273\right)^{4}-\left(\theta_{a m b}+273\right)^{4}\right]}{\left[\left(\theta_{e}+273\right)-\left(\theta_{a m b}+273\right)\right]}
\end{gathered}
$$

where $k_{\text {air }}$ is the thermal conductivity of the air $\left(W m^{-1} K^{-1}\right), \mathrm{G} r$ is the Grashof Number (ratio of buoyancy to viscous force acting on a fluid) and $P r$ is the Prandtl Number (ratio of kinematic viscosity to thermal diffusivity). The value of coefficient $c$ and $m$ are given from Table 2 in [7] with various ranges of Rayleigh Number $(G r \cdot P r) . K_{r}$ is a constant linked to cable installation and $k_{r}$ is the effective emissivity defined by Weedy and El Zayyat in Electra 143 [8]; $\theta_{e}$ and $\theta_{a m b}$ are cable surface temperature and ambient air temperature in ${ }^{\circ} \mathrm{C}$.

With the equation at each node re-arranged into tridiagonal matrix form, the entire cable model can be solved using one set of matrices. Thus, the temperature of each component in the cable at each time step can be calculated, with all the historical load and environment data taken into account. The short-term emergency rating can be determined using this model taking 
advantage of using the measurement data instead of worst case assumptions.

\section{PREDiCTIVE RATINGS}

In a perfect world, in order to help network planning, it is necessary to provide operators with accurate short term current ratings at the day ahead stage. As a result, a predictive rating method has been introduced in this work (Fig. 2). This idea is based on the integration of a day-ahead load forecasting system and a dynamic rating system.

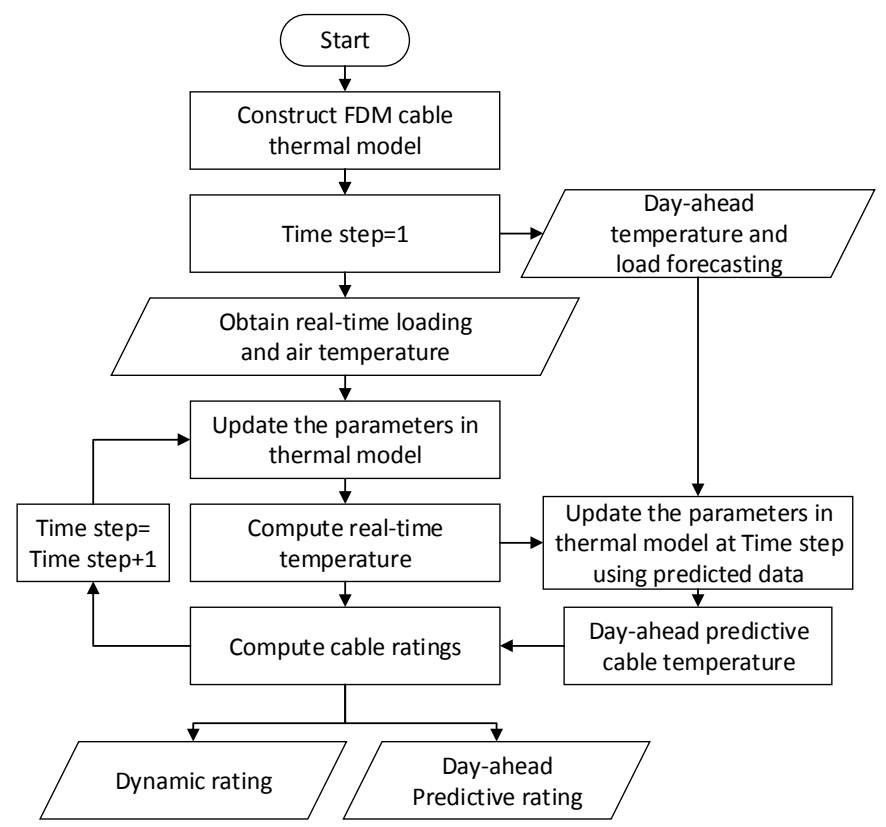

Fig. 2. Flowchart of predictive rating method.

With reference to Fig. 2, the dynamic thermal model used in this system is the FDM model introduced in Section III. The real-time load and ambient air temperature data are measured and used to update the heat losses and thermal parameters in this thermal model. The thermal response of the cable can be computed by this model at each time step. Thus, the dynamic rating, forward from the present time step, can be calculated. In addition, the day-ahead load forecasting are obtained at each time step from a prediction system [9]. This is a load prediction system to forecast load 24 hours ahead from each time-step based on the Support Vector Regression technique. The dayahead temperature prediction is assumed to be available from weather station. Thus, the next $24 \mathrm{hr}$ input load and air temperature data are predicted in advance and are translated into cable temperature prediction by using the dynamic thermal model. Based on the cable temperature prediction, emergency ratings can then be calculated $24 \mathrm{hrs}$ ahead.

\section{EXPERIMENTAL SETUP}

In order to evaluate the accuracy of the dynamic thermal model, a laboratory experiment had been implemented (Fig. 3). The cable sample used in this experiment is a $33 \mathrm{kV}$ single phase XLPE cable with geometry and materials as defined in Table I. This sample is 10 meters long with conductor of two terminals are bolted together which are electrically connected to create a short circuit loop. Single-point-bonding is used to prevent circulating current and the length of the cable sample is not long enough to cause a sheath voltage problem. This cable sample is installed indoors, without influence from the wind or solar radiation. No voltage is applied to the cable, resulting in no dielectric losses within this cable sample.

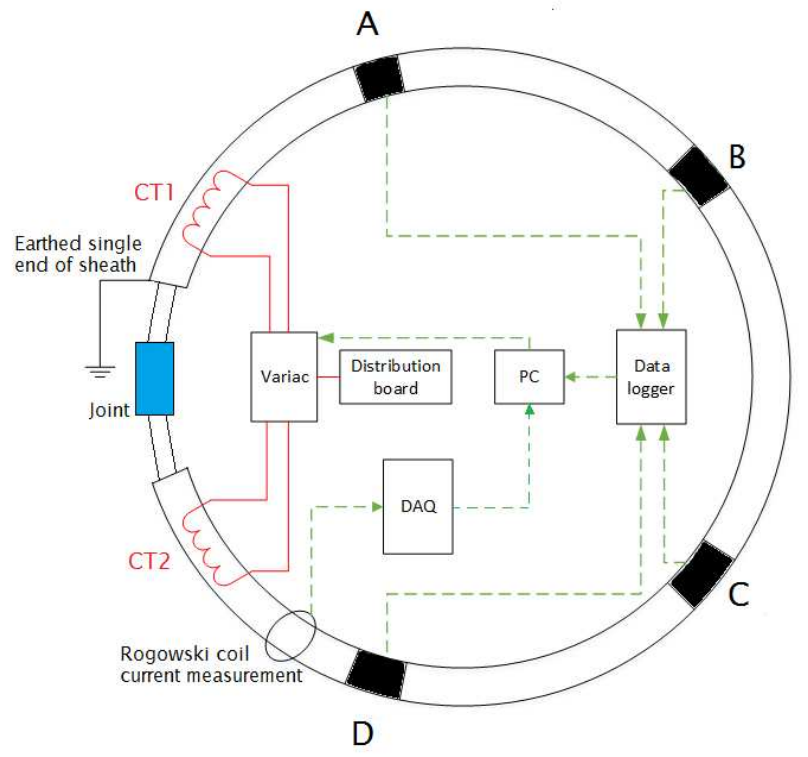

Fig. 3. Experimental setup.

\section{A. Heating and Electrical measurement system}

The heating system includes a motorized variac and two current transformers (CT). The variac is used to control the input current to the primary windings of both two CTs. Then the CTs are used to induce much higher current in the secondary side which is formed by the single short circuit turn of the test cable. Each CT can generate up to 980A secondary current in this experiment. By including a Labview control system to control the motor in the variac, the system can vary the input current to the $\mathrm{CT}$ according to a designed load profile. Thus, the desired daily load cycles can be generated in the cable loop. The current in the conductor is measured using a Rogowski coil. The measurement data is sent to a Labview program via DAQ to adjust the current output from variac and ensure it matches the expected current value.

\section{B. Thermal measurement system}

Thermocouples are placed directly onto the conductor, armour and surface of the test cable to measure the real-time cable temperature data. $\mathrm{K}$ type thermocouple is used in this experiment with the associated precision of $\pm 1.5^{\circ} \mathrm{C}$. In addition, four test sites are installed along the length of the loop (A-D in Fig. 3). Thus the influence from the conditions of cable installation can be quantified. In order to get an adequately high resolution of temperature data, all of the thermocouples are connected to a data acquisition system from Campbell Scientific which includes a CR1000 data logger and a 32 channel relay multiplexer. This system collects data from thermocouples at one minute intervals and stores to a computer at five minutes intervals. 


\section{RESULT ANALYSIS}

Several tests have been done with the models and the lab experiment introduced in previous sections. In this section, the test result of continuous ratings and predictive ratings for this cable sample will be presented.

\section{A. Continuous Ratings}

Solutions for the continuous ratings for this cable in air installation have been determined using two models: the empirical IEC 60287 standard and the FDM model. Inspecting the continuous rating results from Table III, results from these two models are of similar order with the FDM model giving slightly higher rating values than the IEC model. The difference between the two models are within $1.4 \%$.

TABLE III. SEASONAL CONTINUOUS RATING

\begin{tabular}{|c|c|c|}
\hline Seasons & $\begin{array}{c}\text { Rating from IEC } \\
60287(\mathrm{~A})\end{array}$ & $\begin{array}{c}\text { Rating from FDM } \\
\text { model }(\mathrm{A})\end{array}$ \\
\hline Winter & 1630 & 1640 \\
\hline Spring/Autumn & 1534 & 1546 \\
\hline Summer & 1432 & 1453 \\
\hline
\end{tabular}

In order to demonstrate the accuracy of the FDM model, the transient conductor temperature response to a step current from FDM model is compared with the lab experiment. The results in Fig. 4 shows that the FDM model matches well with the experimental data, the conductor temperature has good agreement between the model and experiment during the initial heating phase. After reaching the steady state, the conductor temperature from model matches the maximum conductor temperature from the experiment and is only $4{ }^{\circ} \mathrm{C}$ higher than the average conductor temperature from the experiment.

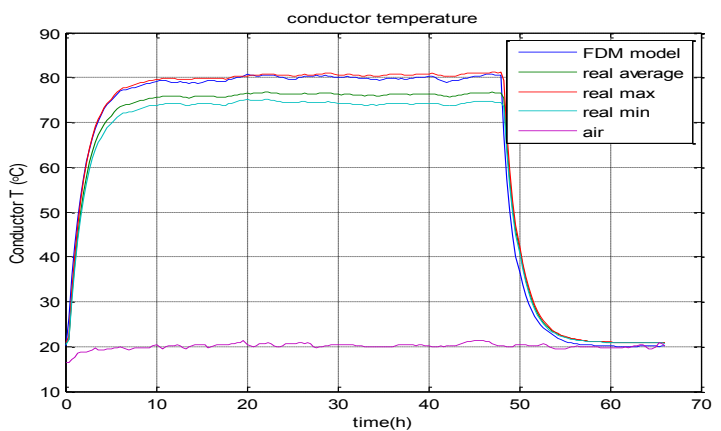

Fig. 4. Thermal response to a step current.

\section{B. Predictive Ratings}

A test has been implemented to demonstrate the predictive rating for cable in free air using the FDM dynamic thermal model. The same load prediction results from [9] are used in this test to predict $3 \mathrm{hr}$ emergency rating at $24 \mathrm{hr}$-ahead horizon. Fig. 5 presents the Cumulative Distribution Function (CDF) of the predictive $3 \mathrm{hr}$ emergency rating errors. It describes the probability that the error of predictive rating is less than a certain value (real ratings minus predictive rating). The $3 \mathrm{hr}$ emergency rating values ranges from $1472 \mathrm{~A}$ to $1620 \mathrm{~A}$ from the direct solution of the FDM model with the given input data, and the percentage of the $24 \mathrm{hr}$-ahead predictive rating errors being contained within $\pm 10 \mathrm{~A}$ (cause less than $1^{\circ} \mathrm{C}$ in 3 hours) is higher than $96 \%$.

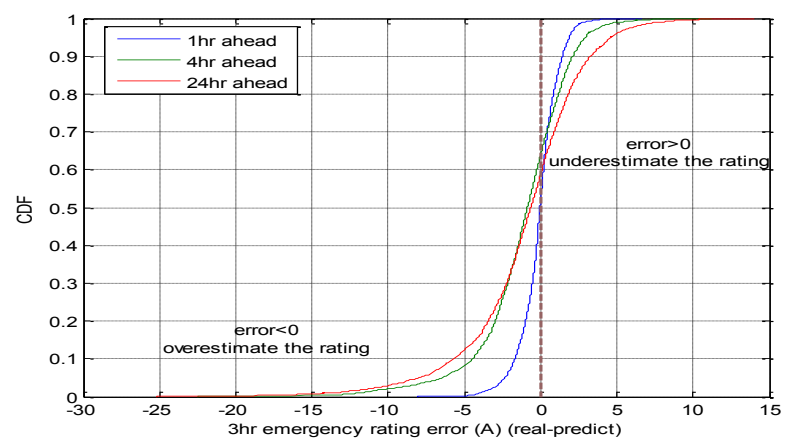

Fig. 5. CDF of predictive $3 \mathrm{hr}$ emergency rating error.

\section{CONCLUSIONS}

In this paper, a dynamic thermal model for a cable in air installation is built using a finite difference method. With the real-time load current and ambient temperature taken into account, the model is able to calculate the real-time temperature and ratings. The lab experiments proved the accuracy of the FDM model. In addition, a day-ahead predictive rating system is introduced and compared with real rating results, more than $96 \%$ of the $24 \mathrm{hr}$-ahead predictive rating errors are contained within $\pm 10 \mathrm{~A}$.

\section{REFERENCES}

[1] S. Walldorf, Steven P.; Ernst, A.; Pancholi, S., "A cost effective solution for increasing ratings on underground transmission cables-a case study,' in Transmission and Distribution Conference, IEEE, 1999, pp. 32-37.

[2] G. J. Anders, A. Napieralski, S. M. Zubert, and M. Orlikowski, "Advanced modeling techniques for dynamic feeder rating systems," Ind. Appl. Conf. 2002. 37th IAS Annu. Meet. Conf. Rec., vol. 2, pp. 1012-1019, 2002..

[3] S. H. Nam, J. M. Lee, K. Y. Kim, S. K. Lee, S. I. Jeon, H. L. Kim, Y. S. Kim, and H. E. Lim, "APPICATION RESULTS OF REAL-TIME AMPACITY ESTIMATION SYSTEM AND INTELLIGENT POWER CABLE SYSTEM," in 7th International Conference on Insulated Power Cables, 2007, p. C5.2.2..

[4] "IEC 60287. Electric cables. Calculation of the current rating - part 1-1: Current rating equations (100\% load factor) and calculation of losses general," 2006 ..

[5] "IEC 60853. Electric cables. Calculation of the cyclic and emergency current rating of cables. part 2: Cyclic rating of cables greater than 18/30 (36)kV and emergency ratings for cables of all voltages," 1989.

[6] V. T. Morgan, "Effect of surface-temperature rise on external thermal resistance of single-core and multi-core bundled cables in still air," IEE Proc. - Gener. Transm. Distrib., vol. 141, no. 3, p. 215, 1994.

[7] V. T. Morgan, "The thermal rating of overhead-line conductors Part I. The steady-state thermal model," Electr. Power Syst. Res., vol. 5, no. 2, pp. 119-139, Jun. 1982..

[8] "Electra 143 - Calculation of temperatures in ventilated cable tunnels," 1992.

[9] R. Huang, J. A. Pilgrim, and P. L. Lewin, "Use of Day-ahead Load Forecasting for Predicted Cable Rating," in IEEE PES ISGT Europe, 2014. 